\title{
RESENHA \\ PARAGUAI. TRANSIÇÃO DEMOCRÁTICA E POLÍTICA EXTERNA
}

\author{
Margarida Nepomuceno ${ }^{(*)}$ \\ Universidade de São Paulo, São Paulo (SP), Brasil
}

O fato de José Aparecido Rolon ter as suas origens ligadas ao Paraguai motivou-o, por certo, a dedicar-se por mais de 10 anos às pesquisas sobre a história recente do país. Primeiro, durante o mestrado no Programa de Pós-graduação em Integração da América Latina, o PROLAM (USP) e, posteriormente, no doutorado, na Faculdade de Filosofia, Ciências e Letras, da mesma universidade. Entretanto, não teria sido esse motivo suficiente se não houvesse um empenho, uma verdadeira peregrinação do pesquisador, iniciada em 2000 até a publicação do presente livro Paraguai. Transição democrática e Política Externa (Annablume, 2011) que descortinou a história que revela o papel significativo de um país, relativamente pequeno, e que é definido por estereótipos, repetidos à exaustão, sem a mínima criatividade ou senso histórico. No mestrado, o interesse em responder à pergunta "O que faz o Paraguai no MERCOSUL"? foi a primeira decisão do autor a fim de contribuir para reverter as prioridades das pesquisas acadêmicas sobre a América do Sul, quase sempre direcionadas ao Brasil e à Argentina. A pesquisa objetivou refletir sobre os limites e possibilidades do Paraguai no processo de Integração Regional que, como demais países de semelhante perfil, têm a sua história geralmente analisada em função dos maiores atores da região.

O livro que ora apresentamos é resultado da tese de doutorado do autor e, objetiva analisar as condições históricas e políticas do stronismo, suas relações com Brasil, Argentina e EUA, bem como o período subsequente, depois de 1989, quando o país inicia o processo de transição democrática. Rolon encaminha suas análises no sentido de buscar as razões internas e da ordem da política externa que teriam sido determinantes para a queda da ditadura militar e para o subsequente período de assentamento de novas bases institucionais. Uma questão como "quais seriam as características da ditadura Stroessner que lhe permitiram permanecer no poder durante 35 anos"? deve ser respondida baseando-se em como foi o processo de formulação dos acordos entre o Partido Colorado e as demais forças do país para a transição democrática e quais as relações que o Paraguai

(*) Mestre, Aluna do curso de doutorado do Programa Interunidades em Integração da América Latina da Universidade de São Paulo. E-mail:<margaridacn@gmail.com>. Recibido en: 19.10.2012, aceito em: 14.10.2014. 
estabeleceu nesse período com os países da região, sobretudo Brasil e Argentina. Naturalmente, também é analisado como eram as relações dos paraguaios com os EUA.

Decidido a valorizar a produção intelectual do país sobre o tema, Rolon utilizou as pesquisas dos centros de documentação e estudos do Paraguai tais como o CPES, Centro Paraguayo de Estudios Sociológicos; o CADEP, Centro de Análisis Difusión de la Economía Paraguaya; o CEPAG, Centro de Estudios Paraguayos Antonio Guasch, dirigido pelo jesuíta Bartomeu Meliá, bem como a produção acadêmica da Universidade Católica de Assunção, a UCA, e da Universidade Nacional de Assunção, a UNA. Junto com os autores clássicos das relações internacionais, tais como Morgenthau, Nye e Huntington, estão também brasileiros, como Chiavenato, Doratiotto, Menezes, e uma vasta gama de intelectuais locais, tais como Estigarribia, Acevedo, Masi, Montoya, Lezcano, Frutose Vera, entre muitos outros, comprovando a existência de uma consistente fortuna crítica acumulada em torno da história recente do país.

Organizado em três capítulos, o livro apresenta inicialmente as condições geográficas e econômicas do Paraguai, apontando suas características determinantes, como a mediterraneidade e as graves implicações econômicas de dependência histórica decorrentes do fato de o Paraguai não ter saídas para o mar. "Um Estado tampão entre as duas maiores nações sul americanas e um dos heartlands na América do Sul”, define Rolon (2011, p. 19), ou como ainda diria o escritor paraguaio Roa Bastos, "uma ilha cercada de terra por todos os lados". Nesse mesmo capítulo, questões como a estrutura econômica do país, com precário desenvolvimento econômico, um mercado de baixo potencial com mão de obra pouco qualificada e o empenho do país de promover a sua inserção em várias frentes de integração regional são analisados. A participação no MERCOSUL, que já havia sido objeto de estudos anteriores do autor, ajuda a compor um quadro que demonstra empenho do Paraguai em efetivar novas parcerias, como dentro da IIRSA (Iniciativa para a Integração da Infraestrutura Regional da América do Sul).Não é preocupação exclusiva do Paraguai a expansão do desenvolvimento econômico para estancar a sangria do desemprego, especialmente depois da década de 90, mas naquele país a situação, segundo dados colhidos pelo autor, é particularmente preocupante com altíssimas taxas de desemprego. Cerca de 70 mil pessoas deixam o país anualmente, a maioria dirigindo-se à Argentina e ao Brasil. Nesse primeiro capítulo, Rolon retrocede no tempo, explica e demonstra em gráficos, as causas históricas e econômicas de um modelo de desenvolvimentos que fez do Paraguai um dos maiores produtores de energia hidroelétrica do mundo e ao mesmo tempo um país onde cerca de $40 \%$ da população vive abaixo da linha da miséria (2011, p. 31-60).

Poder e Política no Paraguai dá nome ao segundo capítulo, e não é à toa que o autor não se refere em nenhum momento a um período de redemocratização do país, e sim de transição para a democracia. Eleições livres ou "normais" como denomina Rolon, só passaram a ocorrer depois de 1998. Frutos e Vera, autores paraguaios, oferecem um quadro político dessa instabilidade: Francia, o ditador de "Yo El Supremo", de Roa Bastos, ficou no poder de 1813, depois da independência do país, até 1840; Carlos Solano Lopes, de 1840 a 1862; Francisco Solano Lopes, o filho, de 1862 a 1870; Morinígo, de 1940 a 1948; e Stroessner de 1954 a 1989, somando juntos quase 110 anos no poder de um país, com cerca de 190 anos de autonomia política (na época da pesquisa). 
Os intervalos entre um governante e outro foram preenchidos pelos "provisoriatos”, geralmente vice-presidentes alçados à categoria de titulares da nação por razões de falecimento, renúncia ou designação do Congresso. Políticos que governaram, em sua maioria, alternando-se entre os Liberais e Colorados, em média, menos de dois anos cada. De 1948 a 1954, houve seis presidentes. Militarização do governo e partidarização do Exército, são características combinadas que, junto a outras, formam um quadro diferenciador da ditadura stronista. As conclusões a que chegou Rolon é que o traço que perpassou todos esses governos foi o uso quase institucionalizado da violência. E nem sempre as elites do país, que representavam os pilares de sustentação desse modelo formado por Exército, burocracia estatal e partidos políticos, sobretudo o Colorado, estiveram de acordo. Em relação à formação do pensamento crítico no Paraguai, Rolon afirma que somente a partir da década de 80 , quando se presencia o retorno dos intelectuais ao país depois do exílio a que foram submetidos, surge uma literatura própria sobre os tempos escuros da ditadura e a análise dessas intrincadas relações políticas e sociais. Até então, a bibliografia internacional caracterizou "esse regime como sendo de uma ditadura personalista tendo sua história”.

No plano externo, Stroessner é tido como hábil negociador com Brasil e Argentina, antes e durante as ditaduras militares nesses países, bem como com os EUA, com quem cerrou fileiras contra o comunismo durante o período da Guerra Fria. Posição que lhe valeu, em contrapartida, apoios financeiros e políticos para firmar-se no poder até fins da década de 70, quando a conjuntura mundial e as condições econômicas internas modificaram-se dando início à derrocada do governo. Dessa forma, o tripé: caudilhismo, forças armadas e partido hegemônico, aliado à exclusão da sociedade civil e às mudanças de ordem externa levam ao golpe militar de 1989 e início do período de transição.

Para o terceiro capítulo, as formulações teóricas do norte-americano Samuel Huntington sobre as transições políticas ocorridas no século XX, bem como as de Norberto Bobbio e O’Donnel, serviram de suporte à análise comparativa entre o processo ocorrido no Paraguai e demais países vizinhos. Huntington defende que os movimentos de transições políticas ocorrido depois de 1970, que ele caracteriza como sendo uma "terceira onda democrática", substituíram regimes autoritários por regimes democráticos e embora, para alguns países, esse período ainda esteja inconcluso, uma nova reconfiguração política se apresenta com a inserção de forças da sociedade civil que estiveram durante muitos anos alijadas, reprimidas e ausentes das decisões do país.

Afirma Rolon que:

quando nos referimos às transições políticas, estamos discutindo um processo que vai muito além do rito de passagem de um regime indesejável - em geral autoritário - para um desejável que, espera-se, seja democrático. Contudo, nem sempre e não necessariamente se tem esse desfecho. (ROLON, 2001, p. 105.)

Rolon demonstra que as tradições políticas, os fatores econômicos, as relações externas que o país mantém e, fundamentalmente, os interesses que movem as forças políticas da sociedade são determinantes para que um processo histórico registre particularidades que são únicas a um determinado país. E, no Paraguai, como bem conclui 
o autor, o fato desse processo ter se iniciado com um golpe palaciano, controlado por setores do próprio poder militar e do Partido Colorado, ambos sustentáculos do antigo regime, coloca esse país em um patamar de análise distinto dos processos que ocorrem nos países da Região. Mais de 20 anos se passaram desde a saída do núcleo stronista e, para Rolón, só com Fernando Lugo (2008- 2012) estaria se dando a ruptura efetiva do domínio de partido único na vida política do país depois de quase 70 anos de hegemonia do Colorado. O autor não tem ilusões a respeito das dificuldades que os novos governantes estão enfrentando para implantar um sistema que garanta a democracia. Vícios remanescentes do antigo sistema, complexidade na formação de uma nova composição de forças decisórias no país, e, ao mesmo tempo, os desafios que estão colocados em um novo cenário latino-americano, trazem riscos e superações, que podem levar o Paraguai a deixar de ser o "primo pobre" da América Latina, e, sobretudo a implantar uma tradição democrática, com garantia de rotatividade no exercício de poder, sem o temor dos antigos "cuartelazos".

A fundamentação da pesquisa de Rolon assenta-se em um corpus teórico capaz de resistir às mudanças históricas e que, ao mesmo tempo, oferece um conhecimento sobre a complexa estrutura de pensamento ou sobre a lógica que move os setores de poder no Paraguai. Algumas semanas depois da elaboração dessa resenha, o Paraguai comprovou que ainda não está livre de sofrer "cuartelazos". Em 22 de junho de 2012, o então presidente Fernando Lugo foi deposto por um arremedo congressual comprometendo o recém e frágil processo de transição democrática no Paraguai. Publicamos abaixo as palavras de esclarecimentos do autor do livro, José Aparecido Rolón, que pode nos ajudar a entender em que medida a lógica que sempre impulsionou a política paraguaia estaria sendo recuperada depois desse episódio.

Sobre os acontecimentos que levaram a deposição do Presidente Fernando Lugo em 2012, o autor tem a dizer:

(...) as razões da queda do presidente Fernando Lugo são inúmeras e variadas. Tem naturalmente a participação e articulação de suas elites internas ligadas aos partidos tradicionais, grandes empresários do agronegócio e também apoio e influência estrangeira como é o caso das multinacionais e dos EUA. Além disso ficou demonstrado a utilização de mecanismos jurídicos como forma de justificar e legitimar a ação. São formas mais contemporâneas de golpes que não se trata de uma novidade, pois algo semelhante já ocorrera em outros países.

Deve-se levar em conta também que a falta de enraizamento social do governo Lugo (embora tenha vindo dos meios não tradicionais ou das elites) não foi capaz de atender as principais demandas da sociedade mais pobre e excluída. Portanto não teve lastro na sociedade mais profunda e carente dos recursos básicos de uma existência digna.

Duro golpe também para a região que, de certo modo, viu-se impotente diante dessa situação, trata-se de um revés levando-se em conta o avanço da democracia nessas paragens. $\mathrm{O}$ Paraguai chegou depois a esse processo iniciado em meados dos anos de 1980 na maioria dos países do Cone Sul. E foi também quem mais rapidamente colocou em xeque essas conquistas.

É certo que nem tudo está perdido; o povo paraguaio tem dado mostras de sua capacidade de luta, resistência e superação. Sobreviveu à Grande Guerra contra a Tríplice Aliança, a di- 
tadura Stroessner e provavelmente encontrará forças para superar mais um golpe perpetrado por suas elites retrógradas. É o desejo de todos nós, estudiosos, admiradores e desejosos de seu desenvolvimento e amadurecimento democrático."(1)

\section{BIBLIOGRAFIA}

ROLON, José Aparecido. Paraguai. Transição democrática e Política Externa. São Paulo: Annablume/ Universidade de São Paulo, 2011.

(1) Trecho de entrevista concedida por José Aparecido Rolon à autora desta resenha. 